\title{
Early outcome of mitral valve replacement through right anterolateral thoracotomy versus standard median sternotomy
}

\author{
Heemel Saha, Redoy Ranjan, Dipannita Adhikary, Jubayer Ahmed, Sanjoy Kumar Saha and \\ Asit Baran Adhikary
}

\begin{abstract}
Article Info
Department of Cardiac Surgery, Faculty of Surgery, Bangabandhu Sheikh Mujib Medical University, Shahbag, Dhaka, Bangladesh (HS, RR, JA, ABA); Al Helal Specialized Hospital, Dhaka (DA); Department of Cardiac Anesthesia, Faculty of Surgery, Bangabandhu Sheikh Mujib Medical University, Shahbag, Dhaka Bangladesh (SKS)

For Correspondence: Asit Baran Adhikary drasit2005@yahoo.com

Received:

Accepted:

Available Online:

15 December 2017

17 February 2018 9 March 2018

ISSN: 2224-7750 (Online) 2074-2908 (Print)

DOI: 10.3329/bsmmuj.v11i1.35584
\end{abstract}

Keywords:

Cosmetic; Mitral valve replacement;

Sternotomy; Thoracotomy

Cite this article:

Saha H, Ranjan R, Adhikary D, Ahmed J, Saha SK, Adhikary AB. Early outcome of mitral valve replacement through right anterolateral thoracotomy versus standard median sternotomy. Bangabandhu Sheikh Mujib Med Univ J. 2018; 11: 94 98.

\section{Copyright:}

The copyright of this article is retained by the author(s) [Atribution CC-By 4.0]

\section{Available at:}

www.banglajol.info

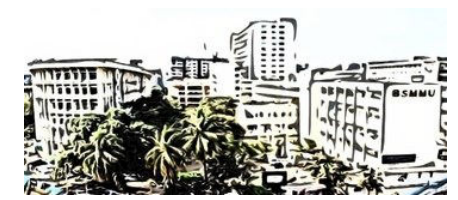

\section{Abstract}

This study was aimed to compare the peri-operative outcomes among the mitral valve replacement using anterolateral thoracotomy $(n=17)$ and standard median sternotomy $(n=17)$ in a single surgeons practice. The mean age was $24.1 \pm 5.3$ years in Group I and $41.0 \pm 11.5$ years in Group II. Female was predominant in Group I. Total operative time and bypass time were significant in both the study groups. Incision scar was not visible in females in Group I but full incision scar was visible in Group II in sitting posture. In Group I patients, majority (52.9\%) patients needed short duration of ICU stay in comparison to Group II, and the difference was statistically significant $(\mathrm{p}<0.05)$ between the two groups. During discharge, $94.1 \%$ wound was well healed in Group I and $70.6 \%$ in Group II. Wound dehiscence was nil in Group I, but $23.5 \%$ patients developed dehiscence in Group II. However, only 5.9\% patient developed unstable sternum in Group II. Cosmetic mitral valve replacement can be done safely through anterolateral thoracotomy and it is cost effective especially for the developing countries.

\section{Introduction}

Heart valve regulates unidirectional flow of blood without reflux and maintain pressure gradients between different chambers. However, the mitral and aortic valve are most vulnerable to rheumatic heart disease. Rheumatic fever leading to heart disease affect mostly mitral valve by causing stenosis of both commissures of the valve with subsequent mitral regurgitation. 1 The compensatory mechanisms of ventricles permit the heart to tolerate these lesions for varying periods of time. Heart failure from mitral stenosis was well recognized by $19^{\text {th }}$ century and the surgical correction began well before the heart lung machine was available. $\underline{1,2}$

In 1956, Lillehei used right thoracotomy approach to repair valvular lesions using cardiopulmonary bypass, and a few years later, first successful prosthetic mitral valve replacement was done in 1961.2,3 In 1965, Jai Si Haung did first mitral valve replacement at Shanghai hospital, China. 3 Moreover, the cosmetic mitral valve surgery has shown in popularity for the last few decades, and currently considered as the safe and effective procedure for most of the patients. At the Brigham and Women's Hospital, they did not involve a complete sternotomy but instead uses a ministernotomy or small thoracotomy incision. 3

There are multiple techniques have been demonstrating to get the surgical approach in mitral valve surgery.

But right minithoracotomy or partial sternotomy is the most commonly practiced minimally invasive approach for the mitral valve surgery.2,4 Now-a-days, port access technique through multiple small incision getting popular day by day but have some demerits like costly, need long training curve and also leaves multiple scars in the groin and chest. $\frac{5}{}$ However, mitral valve surgery through standard median sternotomy, has also increased risk of postoperative instability and osteomyelitis of the sternum in patients with other comorbidity like diabetes. $\frac{4,5}{5}$ The aim of right anterolateral thoracotomy approach is to reduce the morbidity, short hospital stays, early discharge and short rehabilitation time. $.5-7$

A study conducted by Ganie et al. (2013) comparing anterolateral thoracotomy against standard median sternotomy for mitral valve surgery and observed that the study populartions of both groups were comparable in terms of age, sex, NYHA class of heart failure and ejection fraction. 6 Thoracotomy shows better 
outcome than the sternotomy in points of postoperative intensive care unit stay, early ambulation, less infection rate, faster recovery and also cost effective. Thoracotomy leads better cosmetic results especially in females and this made it more convenient psychologically. 8-10 This study was intended to compare the short-term outcome between standard median sternotomy and right anterolateral thoracotomy for mitral valve replacement.

\section{Materials and Methods}

This prospective study was conducted in between January 2015 to March 2016 at the Cardiac Surgery Department, Bangabandhu Sheikh Mujib Medical University in a single surgeons practice. Total 34 patients were evaluated and categorized into two groups. There were 17 patients in Group I (thoracotomy) and 17 patients in Group II (median sternotomy). Patient's with severely symptomatic mitral valvular disease including both stenosis and regurgitation were enrolled in this study except patients having previous mitral valve replacement, bleeding diathesis, co-morbidity such as diabetes, chronic kidney disease and thyroid disease.

Statistical analyses were carried out using the Statistical Package for Social Sciences (SPSS) and categorical variables were presented in the form of frequency and percentage. However, quantitative data was presented in the form of mean and standard deviation. Fisher's exact test and Chisquare test were used to analyze the categorical variables. Student t-test or unpaired t-test was used for continuous variables to test the statistical difference. $\mathrm{P}$ values $\leq 0.05$ was considered as statistically significant.

\section{Surgical procedure}

The study group was comprised of $50 \%$ of patients who undergone mitral valve replacement via right anterolateral thoracotomy and another $50 \%$ patients who were subjected to valve surgery through sternotomy. Common general anesthetic procedure with routine venous and arterial monitoring were used to both groups. In thoracotomy group, surgical incision was done using right sub-mammary line extending from the lateral border of the sternum up to right anterior or mid axillary line. In females, breast tissue was gently mobilized and thoracic cavity was accessed through right $4^{\text {th }}$ intercostal space. Cardiopulmonary bypass was then established in the usual technique and after cooling to $32^{\circ} \mathrm{C}$, a long curved clamp used to cross clamp the aorta and blood cardioplegia was delivered through aortic root cannula. Then the left atriotomy was done through interatrial groove and diseased valve excised and replaced with a prosthetic heart valve using continuous suture technique with 2-0 prolene. After valve positioning, left atriotomy was closed by prolene (4-0) suture and de-airing done before removal of the cross clamp. Weaning and de-cannulation were performed using standard technique in both the groups of patients. Proper hemostasis was done and protamine infusion used to reverse the action of heparin. Chest was closed in layers leaving a two drain tube in situ. In another group, the operative steps were same except the approach, which was through the standard median sternotomy.

Patients were electively ventilated up to the fulfilment of extubation criteria. Post-extubated patients were transferred to step down unit after full assessment of the hemodynamics and general condition of the patients. Oral anticoagulant prescribed just after removal of the chest drain tube with $10 \mathrm{mg}$ warfarin sulfate as a stat dose and then $5 \mathrm{mg}$ daily. Prothrombin time was done after 72 hours of initial dose of warfarin sulfate and then the dose was adjusted to maintain international normalized ratio (INR) within 3.0 to 3.5. Same intravenous antibiotic protocol was administered during operation and was continued up to $5^{\text {th }}$ post-operative day. Then an oral form was continued till hospital staying. If any complication such as sepsis, wound discharge occurred, then antibiotics was changed according to the culture sensitivity reports.

\section{Results}

The mean age was $24.1 \pm 5.3$ years in Group I and $41.0 \pm 11.5$ years in Group II, which was significantly $(p<0.05)$ higher. Female was predominant in Group I (76.5\%) and male was predominant in Group II (70.6\%). Majority of the patients were housewives and married. Vital parameters were statistically insignificant between the two groups (Table I). It was observed that the mean cross clamp time was $35.4 \pm 7.5 \mathrm{~min}$ in Group I and $34.4 \pm 3.7$ min in Group II. However, the mean total operative time was $229.5 \pm 28.1 \mathrm{~min}$ in Group I, which was significantly higher than in Group II (Table II).

The average length of incision was $10.2 \pm 1.2$ and $13.5 \pm 1.75 \mathrm{~cm}$ in Group I and II respectively. However, the incision scar was not or less visible in the majority of patients especially in females in Group I as it was hidden by the breasts but the full incision scar was visible in $100 \%$ patient's in Group II. The incidence of wound dehiscence was statistically significant between the two groups. However, only $5.9 \%$ patients developed mediastinitis and unstable sternum in Group II. The difference was not statistically significant $(\mathrm{p}>0.05)$ between the two groups (Table III). 


\begin{tabular}{|c|c|c|}
\hline \multicolumn{3}{|c|}{ Table I } \\
\hline \multicolumn{3}{|c|}{ Distribution of particulars of the study groups } \\
\hline Demographic variables & $\begin{array}{l}\text { Group I } \\
(\mathrm{n}=17)\end{array}$ & $\begin{array}{c}\text { Group I } \\
(\mathrm{n}=17)\end{array}$ \\
\hline Age (years) mean \pm SD & $24.1 \pm 5.3$ & $41.0 \pm 11.5$ \\
\hline \multicolumn{3}{|l|}{ Sex } \\
\hline Male & 4 & 12 \\
\hline Female & 13 & 5 \\
\hline \multicolumn{3}{|l|}{ Occupation } \\
\hline House wife & 7 & 4 \\
\hline Service & 3 & 6 \\
\hline Business & 2 & 2 \\
\hline Farmer & 0 & 4 \\
\hline Student & 5 & 1 \\
\hline \multicolumn{3}{|l|}{ Marital Status } \\
\hline Married & 9 & 15 \\
\hline Unmarried & 8 & 2 \\
\hline Vital parameters (Mean $\pm S D$ ) & & $($ Mean $\pm \mathrm{SD})$ \\
\hline Pulse (bpm) & $83.5 \pm 9.3$ & $85.1 \pm 6.6$ \\
\hline Systolic BP (mmHg) & $\begin{array}{r}107.7 \pm \\
12.0\end{array}$ & $113.5 \pm 10.0$ \\
\hline Diastolic BP (mmHg) & $74.6 \pm 9.1$ & $74.3 \pm 12.9$ \\
\hline
\end{tabular}

\begin{tabular}{|c|c|c|}
\hline \multicolumn{3}{|c|}{ Table II } \\
\hline \multicolumn{3}{|c|}{ Per-operative findings of study population } \\
\hline Per-operative variables & $\begin{array}{c}\text { Group-I } \\
(\mathrm{n}=17) \\
\text { Mean } \pm \text { SD }\end{array}$ & $\begin{array}{c}\text { Group-II } \\
(\mathrm{n}=17) \\
\text { Mean } \pm \text { SD }\end{array}$ \\
\hline Cross clamp time (min) & $35.4 \pm 7.5$ & $34.4 \pm 3.7$ \\
\hline Total operation time (min) & $229.5 \pm 28.1$ & $197.8 \pm 45.0$ \\
\hline Total bypass time (min) & $81.1 \pm 23.0$ & $74.7 \pm 15.6$ \\
\hline Temperature $\left({ }^{\circ} \mathrm{C}\right)$ & $32.9 \pm 1.3$ & $32.9 \pm 0.9$ \\
\hline Adequate surgical exposure & 17 & 17 \\
\hline Conversion & 17 & 17 \\
\hline
\end{tabular}

\section{Discussion}

In this present study, it was observed that most $(64.7 \%)$ of the patients were in 3 rd decade in group I and $35.3 \%$ in $4^{\text {th }}$ decade in Group II. Pulse and blood pressure were almost alike between two groups. Regarding sex distribution, female was predominant $(76.0 \%)$ in Group I and male predominant $(70.6 \%)$ in Group II. However, majority of the patients were housewives and service holder. In this study, mean total operative time was $229.5 \pm 28.1$ min varied in Group I and $197.8 \pm 45.0 \mathrm{~min}$ in Group II. Though all patients had adequate surgical exposure, however mean total bypass was significantly higher in Group I. It was observed that, incision scar not visible in $100 \%$ cases in Group I but full incision scar was visible in Group II. Postoperative ICU stay was significantly higher in Group II patients. Wound was well healed in $94.1 \%$ in Group I and 70.6\% in Group II.

In a study, El-Fiky et al. (2000)observed that the mean age of study population was $22 \pm 10$ years, which is comparable with the current study. 9 However, Ganie et al. (2013) and Aybek et al. (2006) found the mean age was $44.4 \pm 8.2$ and $56 \pm 14$ years respectively in right anterolateral thoracotomy, which is higher with the current study. .11 Similarly, in another study Grossiet al. was found the mean age $55.3 \pm 17.2$ years in standard sternotomy approach, which also higher with the current study. $\underline{12}$ The higher mean age and age range maybe due to geographical variations, ethnic differences, genetic causes and different lifestyle in their study patients.6,9,11,12 In a study, Grossi et al. (1999) found male was $55.0 \%$ in standard sternotomy approach, which is comparable with this study. $\underline{.2}$ Moreover, Kumar et al. (1999) also observed 38 patients undergone mitral valve replacement using right anterior thoracotomy and majority of patients were young women in their study, which is also similar to other published articles. $\underline{6,9,13}$

Ganie et al. (2013) observed the mean cross-clamp time and bypass time was 41.7 and $83.3 \mathrm{~min}$ respectively in their study using anterolateral thoracotomy approach. Conversion rate to median sternotomy was very minimum for proper exposure to mitral valve, which is concordance to other findings also. $.6,11,14,15$ In thoracotomy, cross-clamp time was less because of easy approach to left atrium even with a small left atrium. In a study, Aybek et al. (2006) found the duration of early postoperative intensive care unit (ICU) stay was 18 hours in right anterolateral thoracotomy, which is consistent with other studies.11,12,16,17 Aybeket al. found the mean intensive care unit and hospital stay were 18 hours and 8.1 days, respectively in right anterolateral thoracotomy but Chiu et al. (2006) reported that the mean ICU stay was 1.8 days ranged from 1-8 days. $\frac{11,18}{1 n}$ this study, it was observed that majority of the patients had less than $10 \mathrm{~cm}$ length of incision. Mean length of incision was found $10.2 \pm 1.2 \mathrm{~cm}$ with ranged from 8.5 to $12.5 \mathrm{~cm}$, which is also similar to others findings $6,9,12$ but some authors found the incision was more, which differ with the current study, may be due to racial, ethnic differences and genetic causes. $\underline{11,15,18}$

The incidence of wound infections and septic complications is lower with a thoracotomy than with a median sternotomy. In this series, it was observed that wound dehiscence was significantly higher in Group II at $4^{\text {th }}$ and $6^{\text {th }}$ post-operative day. Similarly, Iribarne et al. (2010) found sepsis only in 


\section{Table III}

\begin{tabular}{|c|c|c|c|}
\hline \multicolumn{4}{|c|}{ Post-operative data of study population } \\
\hline \multicolumn{2}{|c|}{ Post-operative outcome } & $\begin{array}{l}\text { Group I } \\
(\mathrm{n}=17)\end{array}$ & $\begin{array}{c}\text { Group II } \\
(\mathrm{n}=17)\end{array}$ \\
\hline \multicolumn{2}{|c|}{ ICU stay (days) } & $2.8 \pm 0.3$ & $4.3 \pm 0.5$ \\
\hline \multicolumn{2}{|c|}{ Length of incision $(\mathrm{cm})($ Mean \pm SD) } & $10.2 \pm 1.2$ & $13.5 \pm 1.8$ \\
\hline \multicolumn{4}{|c|}{ Visibility of incision scar } \\
\hline \multicolumn{2}{|l|}{ Visible } & 0 & 17 \\
\hline \multicolumn{2}{|c|}{ Not or less visible } & 13 & 0 \\
\hline \multicolumn{4}{|c|}{ Wound dehiscence } \\
\hline \multirow[t]{2}{*}{$1^{\text {st }}$ POD } & Yes & 0 & 0 \\
\hline & No & 17 & 17 \\
\hline \multirow[t]{2}{*}{$4^{\text {th }} \mathrm{POD}$} & Yes & 0 & 4 \\
\hline & No & 17 & 13 \\
\hline \multirow[t]{2}{*}{$6^{\text {th }}$ POD } & Yes & 0 & 4 \\
\hline & No & 17 & 13 \\
\hline \multicolumn{4}{|c|}{ Mediastinitis } \\
\hline \multirow[t]{2}{*}{$1^{\text {st }}$ POD } & Yes & 0 & 0 \\
\hline & No & 17 & 17 \\
\hline \multirow[t]{2}{*}{$4^{\text {th }}$ POD } & Yes & 0 & 0 \\
\hline & No & 17 & 17 \\
\hline \multirow[t]{2}{*}{$6^{\text {th }}$ POD } & Yes & 0 & 1 \\
\hline & No & 17 & 16 \\
\hline \multicolumn{4}{|c|}{ Unstable sternum } \\
\hline \multirow[t]{2}{*}{$1^{\text {st }}$ POD } & Yes & 0 & 0 \\
\hline & No & 17 & 17 \\
\hline \multirow[t]{2}{*}{$4^{\text {th }} \mathrm{POD}$} & Yes & 0 & 0 \\
\hline & No & 17 & 17 \\
\hline \multirow[t]{2}{*}{$6^{\text {th }}$ POD } & Yes & 0 & 1 \\
\hline & No & 17 & 16 \\
\hline
\end{tabular}

$1.8 \%$ in sternotomy group. .19 The minimally invasive group had a significantly lower incidence of sepsis and wound complications, required fewer frozen plasma transfusions, and had a shorter hospital stay. $.3,6,18,19$ Though the incidence of mediastinitis is uncommon but possible after having a partial sternotomy.12, 19,20 Grossi et al. reported an incidence mediastinitis of $0.9 \%$ for mini-thoracotomy and $5.7 \%$ for sternotomy cases, whereas Felger et al. (2002) reported no significant differences. $\frac{12,20}{2}$ In this study, only $5.9 \%$ patient developed mediastinitis and unstable sternum in standard sternotomy group, which is concordance to other artcles. $6,9,18,20-$ $\underline{23}$

This study compared the early outcome of mitral valve replacement using right anterolateral thoracotomy versus standard median sternotomy. Using thoracotomy approach, overall surgical field exposure was adequate, and no technical difficulty was encountered during aortic and venous cannulation; also atriotomy, valve excision and replacement was comfortable. Though, total time of operation was slightly longer in Group I, however prolonged ICU stay in Group II, but cross clamp time, total bypass time, temperature and condition of wound during discharge were almost alike between two groups.

\section{Conclusion}

Mitral valve replacement via anterolateral thoracotomy is a good option for better post-operative outcome, cosmetic purpose and also cost effective.

\section{Ethical Issue}

Ethical clearance for the study was taken from the concerned departmental academic and technical committee and also from the Institutional Review Board. All patients enrolled in this study were explained about the nature and purpose of the study and about the questionnaire used for this study. Moreover, a written informed consent was taken and a standardized semi-structured data collection sheet used to gather necessary information of study population. After getting consent from the ethical committee and obtaining written informed consent of the patients after detailed counselling regarding the prospect and consequence of each procedure the study was carried out and were followed-up for a period during hospital staying.

\section{Conflict of interest}

There is no conflict of interest.

\section{References}

1. Cohn LH, Adams DH, Couper GS. Minimally invasive cardiac valve surgery improves patient satisfaction while reducing costs of cardiac valve replacement and repair. Ann Cardiothorac Surg. 1997: 4: 421-28.

2. Bisbos AD, Spanos PK. Mitral valve regurgitation: Surgical treatment. Hellenic J Cardiol. 2003; 1: 41826.

3. Schmitto JD, Mokashi SA, Cohn LH. Minimallyinvasive valve surgery. J Am Coll Cardiol. 2010; 56: 455-62. 
4. Thompson MJ, Behranwala A, Campanella C, Walke WS, Cameron EW. Immediate and long-term results of mitral prosthetic replacement using a right thoracotomy beating heart technique. Eur J Cardiothorac Surg. 2003; 24: 47-51.

5. Cosgrove D, Sabik J, Navia J. Minimally invasive valve operations. Ann Thorac Surg. 1998; 65: 153539.

6. Ganie FA, Ahangar AG, Shah ZA, Lone GN, Lone H, Wani ML, Dar AM, Bhat MA, Singh S, Whaid S, Kawoosa NUN. Right anterolateral thoracotomy a minimally invasive approach to mitral valve replacement. Muller J Med Sci Res. 2013; 4: 53-56.

7. Nissinen J, Biancari F, Wistbacka JO, Peltola T, Loponen P, Tarkiainen P, Virkkilä M, Tarkka M. Safe time limits of aortic cross-clamping and cardiopulmonary bypass in adult cardiac surgery. Perfusion 2009; 24: 305-07.

8. Modi P, Hassan A, Chitwood WR. Minimally invasive mitral valve surgery: A systematic review and meta-analysis. Eur J Cardiothorac Surg. 2008; 8 943-52.

9. El-Fiky MM, El-Sayegh T, El-Beishry AS, Aziz MA, Enein HA, Waheid S, Sallam IA. Limited right anterolateral thoracotomy for mitral valve surgery. Eur J Cardiothorac Surg. 2000; 17: 710-13.

10. Meluh US, Inan K, Baltalarli K, Tarhan A, Ege T, Süngün M. Mitral valve operations with right anterior mini-thoracotomy. Int J Thorac Cardiovasc Surg. 2000; 3: 2-3.

11. Aybek T, Dogan S, Risteski PS, Zierer A, Wittlinge T, Wimmer-Greinecker G, Moritz A. Two hundred forty minimally invasive mitral operations through right mini thoracotomy. Ann Thorac Surg. 2006; 81: 1618-24.

12. Grossi EA, Galloway AC, Ribakove GH. Minimally invasive port-access surgery reduces operative morbidity for valve replacement in the elderly. Heart Surg Forum. 1999; 2: 212-15.

13. Kumar AS, Prasad S, Rai S, Saxena DK. Right thoracotomy revisited. Tex Heart Inst J. 1993; 20: 4042.

14. Srivastava AK, Garg SK, Ganjoo AK. Approach for primary mitral valve surgery: Right anterolateral thoracotomy or median sternotomy. J Heart Valve Dis. 1988; 7: 370-75.

15. Mishra YK, Malhotra R, Mehta Y, Sharma KK, Kasliwal RR, Trehan N. Minimally invasive mitral valve surgery through right anterolateral mini thoracotomy. Ann Thorac Surg. 1999; 68: 1520-24.

16. Zapolanski A, Korver K, Pliam MB, Shaw RE, Mengarelli LM. Mitral valve surgery via a right anterior mini-thoracotomy with central aortic cannulation and no endoscopic assistance. Heart Surg Forum. 2002; 4: 445-53.

17. Adhikary AB, Hasan K, Saha SK, Raha SK, Saha H Ranjan R, Sarker SR, Mandal S, Hazra N. Mitral valve replacement after closed mitral commisurotomy. Bangladesh J Cardiovasc Thorac Surg. 2016; 1: 3-6.

18. Chiu KM, Lin TY, Li SJ, Chen JS, Chu SH. Less invasive mitral valve surgery via right minithoracotomy. J Formos Med Assoc. 2006; 105: 71521.

19. Iribarne A, Russo MJ, Easterwood R, Hong KN, Yang J, Cheema FH, Smith CR, Argenziano $M$. Minimally invasive versus sternotomy approach for mitral valve surgery: A propensity analysis. Ann of Thorac Surg. 2010; 90:1471-78.

20. Felger JE, Nifong LW, Chitwood WR. The evolution of and early experience with robot-assisted mitral valve surgery. Surg Laparosc Endosc Percutan Tech. 2002; 12:58-63.

21. Seeburger J, Borger MA, Falk V, KuntzeT, Czesla M, Walther T, Doll N, Mohr FW. Minimal invasive mitral valve repair for mitral regurgitation: Results of 1339 consecutive patients. Eur J Cardiothorac Surg. 2008; 34: 760-65.

22. Aftabuddin M. Outcome and quality of life of patients following valve replacement surgery: Predictors of healthy survival. Cardiovasc J. 2017; 10: 21-30.

23. Husain SS, Ahmed CM, Sohan AM, Mahmud S, Rahman MM, Zaman SMM, Khaled MFI, Osmany DMMF. Short term clinical outcome in patients with mitral valve replacement with or without preservation of subvalvular apparatus. Univ Heart J. 2016; 12: 3-7. 